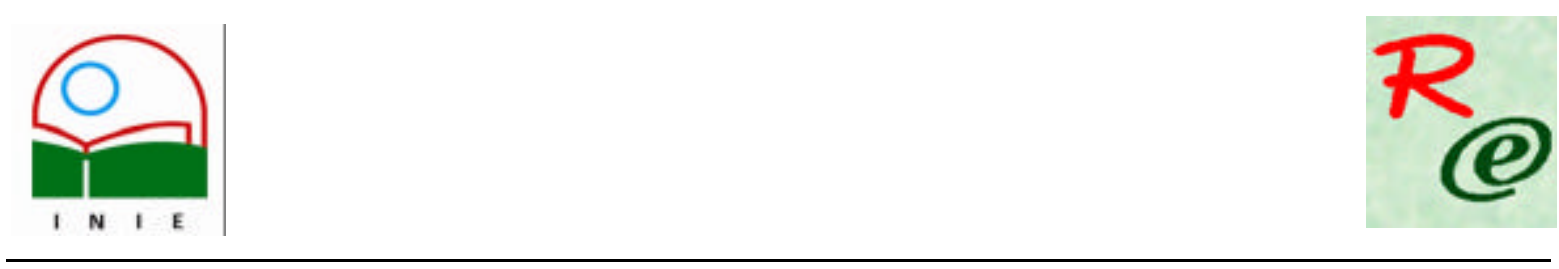

Actualidades Investigativas en Educación

Revista Electrónica publicada por el

Instituto de Investigación en Educación

Universidad de Costa Rica

ISSN 1409-4703

http://revista.inie.ucr.ac.cr

COSTA RICA

\title{
EL LOCUS DE DISTRIBUCION COMO COROLARIO DEL LOCUS DE CONTROL
}

THE LOCUS OF DISTRIBUTION AS A COROLLARY TO THE LOCUS OF CONTROL

Volumen 9, Número 2

pp. $1-15$

Este número se publicó el 30 de agosto 2009

\author{
Luisa Mayoral \\ Bernard Gangloff \\ María del Carmen Romero
}

La revista está indexada en los directorios:

LATINDEX, REDALYC, IRESIE, CLASE, DIALNET, DOAJ, E-REVIST@S,

La revista está incluida en los sitios:

REDIE, RINACE, OEI, MAESTROTECA, PREAL, HUASCARAN, CLASCO 


\title{
EL LOCUS DE DISTRIBUCION COMO COROLARIO DEL LOCUS DE CONTROL

\author{
THE LOCUS OF DISTRIBUTION AS A COROLLARY TO THE LOCUS OF CONTROL
}

\section{Luisa Mayoral Bernard Gangloff María del Carmen Romero}

\begin{abstract}
Resumen: Este es un artículo científico acerca del Locus de Distribución, surgido de un estudio realizado con una población de docentes y alumnos universitarios. Respecto de los primeros, se ha indagado acerca de las atribuciones que se realizaban en torno a las recompensas y sanciones, que ellos distribuían a sus alumnos. Respecto de los segundos, se ha buscado determinar la valoración que estos realizaban de sus profesores, en términos de aquellas atribuciones. Para ello, se utilizaron dos paradigmas clásicamente empleados para verificar la existencia de una norma: el paradigma de la autopresentación (docentes), y el paradigma de los jicios (alumnos). La cuestión planteada fue determinar si en el caso de los comportamientos distributivos de refuerzos, las causas se atribuían a variables externas -en particular a los receptores de esos refuerzos-y si esas formas de atribución eran conocidas y valoradas o no, por los alumnos. De los resultados, surgió la confirmación de nuestra hipótesis de explicaciones externas en materia de comportamientos distributivos de sanciones en el ámbito de la docencia y la valoración positiva de estas atribuciones por los alumnos.
\end{abstract}

Palabras clave: INTERNALIDAD/EXTERNALIDAD, LOCUS DE DISTRIBUCION, LOCUS DE CONTROL, NORMA DE OBEDIENCIA, DOCENTES.

\begin{abstract}
This one is a scientific article brings over of the Locus of Distribution, arisen from a study realized with a population of teachers and university pupils. Respect of the first ones, it has been investigated brings over of the attributions that were concerning around the reinforcements which they were distributing to pupils. Respect of the second ones, one has sought to determine the valuation that these realized of the teachers, in terms of those attributions. For it, two paradigms were in use classic used to check the existence of a norm: the paradigm of the auto-presentation (teachers), and the paradigm of the judgments (pupils) The raised question was to determine if in case of the distributive behaviours of reinforcements, the reasons were assuming to external variables especially individual, to the recipients of these reinforcements - and if these forms of attribution were known and valued or not, for the pupils. Of the results, there arose the confirmation of our hypothesis of external explanations as for distributive behaviours of sanctions in the area of the teaching and the positive valuation of hese attributions for the pupils.
\end{abstract}

Key words: INTERNALITYIEXTERNALITY, LOCUS OF DISTRIBUTION, LOCUS OF CONTROL, NORM OF OBEDIENCE, TEACHERS

\footnotetext{
Doctorada en Ciencias Economicas, Universidad Nacional del Centro de la Provincia de Buenos Aires, Argentina. Labora en la Universidad Nacional del Centro de la Provincia de Buenos Aires, Tandil, Argentina. Dirección electrónica:Imayoral@econ.unicen.edu.ar

${ }^{2}$ Post doctorado en Psicologia, Universidad de Rouen, France. Labora en la Université de Rouen, France. Dirección electrónica: bernard.gangloff@univ-rouen.fr

${ }^{3}$ Ingeniera en Sistemas, Universidad Nacional del Centro de la Provincia de Buenos Aires. Labora en la Universidad Nacional del Centro de la Provincia de Buenos Aires. Tandil, Argentina. Dirección electrónica: romero@econ.unicen.edu.ar
}

Artículo recibido: 18 de noviembre, 2008

Aprobado: 10 de agosto, 2009

Volumen 9, Número 2, Año 2009, ISSN 1409-4703 


\section{Introducción}

La vida cotidiana se compone de eventos positivos (éxitos) y negativos (fracasos), que pueden, desde un punto de vista causal, ser clasificados en dos categorías: eventos resultado de factores internos (esto es, éxitos o fracasos obtenidos en razón de nuestra personalidad o comportamiento) y eventos provenientes de factores externos (el azar, la decisión arbitraria de alguien, etc.). Esta dicotomización internalidad-externalidad, remite a aquella de Rotter (1966) y Lefcourt (1966) acerca del Locus de Control ${ }^{4}$. Numerosos estudios han sido realizados para estudiar el tipo preferencial de causalidad que utilizamos para explicar los acontecimientos que nos suceden (o lo que les ocurre a otros en relación con nosotros), siempre desde el punto de vista del receptor de los acontecimientos.

Sin embargo, existe un dominio o plano totalmente pasado por alto (al menos en nuestro conocimiento): la explicación de esos acontecimientos desde el punto de vista de un eventual distribuidor de esos acontecimientos. Desde un punto de vista lógico, si el que recibe un refuerzo aplicado por un agente externo atribuye evento a sí mismo (por su personalidad o su comportamiento), es decir, de manera interna, podríamos esperar, entonces, que el distribuidor de ese refuerzo lo atribuya en el mismo sentido, esto es, al receptor. Ciertamente, nos ha parecido interesante examinar las atribuciones realizadas por los distribuidores de refuerzos a partir de una primera hipótesis de trabajo que atribuya las causas de estos refuerzos a quienes los reciben. La pertinencia de tal hipótesis parece ser particularmente alta en el caso de los refuerzos negativos, y remite a ciertos discursos de jefes de empresas, o gobernantes y políticos que justifican despidos, reducción de salarios, o sacrificios exigidos a un grupo social en la falta de esfuerzo suficiente de parte de sus empleados o gobernados, por la globalización, o por razones supra nacionales, dejando así fuera toda posibilidad de responsabilización del agente distribuidor de estos refuerzos ${ }^{5}$.

\footnotetext{
4 Denominación que puede dar lugar a confusión. Así, por ejemplo, el hecho de que nuestra personalidad o comportamiento sean de carácter interno, no significa que ejerzamos un efectivo control sobre ellos (cf. Gangloff, 1998, p. 42 nota 1).

5 Una pequeña aclaración en materia de temáticas científicas. Rotter formula el concepto de LOC a partir de plantearse una cuestión concreta: ¿por qué ciertos individuos no logran para sí mismos lo necesario para progresar socialmente? Y Rotter propone una explicación en términos de LOC: aquellos que no lo logran son individuos externos, individuos que consideran que no tienen ninguna influencia sobre los acontecimientos que les suceden. Esto significa que Rotter se encuentra posicionado, tanto respecto de la pregunta como de la respuesta, desde el punto de vista del receptor de esos acontecimientos (posiblemente influido por una cierta cultura liberal característica del entorno). La orientación que aquí planteamos es inversa (posiblemente influidos por alternativas ideológicas diferentes), orientación a partir de la cual nos preguntarmos por qué ciertos individuos detentadores de un status dominante (por ejemplo con el poder de sancionar a otros) no favorecen el progreso social de otros, y como lo justifican. Volumen 9, Número 2, Año 2009, ISSN 1409-4703
} 
La pregunta que nos formulamos es entonces la siguiente: en términos de un agente que aplica sanciones, ¿Este agente se reconoce él mismo como fuente de aquellas sanciones, o rechaza esa responsabilidad, atribuyéndola al propio receptor, o a alguna otra causa externa? Esta pregunta remite a una dicotomización interna/externa, pero una dicotomización ahora aprehendida por parte del distribuidor o agente aplicador de esas sanciones. No nos situamos, entonces, dentro del dominio clásico del LOC, sino desde lo que ha sido denominado por Gangloff (2004) como: LOD Locus of Distribución, o LOC examinado desde el distribuidor).

Ahora bien, dejemos por un momento el plano de la explicación de los refuerzos, para pasar a la explicación de los comportamientos. Se sabe que al tratar de determinar la razón de nuestros comportamientos (o la razón de bs comportamientos de otros en relación con nosotros) podemos hacer referencia a explicaciones internas (la personalidad o voluntad del actor, por ejemplo) tanto como a factores externos (el azar, el comportamiento de una tercera persona, etc.). Es así que Heider (1944) ha llamado "atribución" a estas formas de búsqueda de causas internas o externas de los comportamientos. El objeto de la atribución es entonces bien diferente al objeto del LOC (en un caso explicamos comportamientos y, en el otro, los éxitos o fracasos), dando lugar a una serie de investigaciones específicas en este sentido. Luego, la atribución y el LOD podrían superponerse: es el caso que se da cuando los comportamientos a explicar son comportamientos distributivos de sanciones (el LOD o más exactamente los comportamientos distributivos de sanciones podrían ser considerados como una categoría particular de la atribución comportamental). Sin embargo, hasta ahora los trabajos al respecto son inexistentes (al menos en nuestro conocimiento).

Ahora bien, si nos centramos sobre los resultados obtenidos en materia de LOC por una parte, y sobre el plano de atribución por la otra, observamos en los dos casos una frecuencia significativamente importante de las explicaciones internas en relación con las explicaciones externas: es decir que, para explicar lo que nos pasa (LOC) acudimos preferentemente a nosotros mismos, evocando por ejemplo, nuestra personalidad o nuestros comportamientos (cf. los informes de Lerner, 1965; de Lerner y Simmons, 1966; de Langer, 1975; etc.), y para explicar nuestros comportamientos (atribución) acudimos esencialmente también a elementos internos, como nuestra personalidad o nuestra voluntad (cf. las revisiones de Ross, 1977; de Jones, 1979; etc.). Es importante señalar que se recurre a estos dos tipos de explicaciones internas aún en los casos en que los determinantes objetivos en cuestión sean externos. Esta discordancia ha sido interpretada en términos de Volumen 9, Número 2, Año 2009, ISSN 1409-4703 
sesgo, o error (Nietzsche, ed. Francesa, 1968, p. 163; Ross, 1977), y atribuído a matices de personalidad.

Sin embargo, ha surgido una interpretación alternativa que no refiere a un sesgo sino

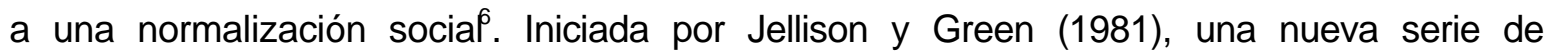
investigaciones se han ido desarrollando, en la búsqueda de evidencia de una valorización social de las explicaciones internas (tanto en materia de LOC como en el dominio de la atribución). En otros términos, si aducimos -inclusive, contra toda evidencia objetiva preferentemente respuestas internas que externas, esto podría ser porque este tipo de respuestas serán socialmente valorizadas. Así, estas respuestas traducirían nuestra interiorización de una norma social particular: la norma de internalidad (cf., para una revisión, Dubois, 1994).

La validez de esta norma, sin embargo, ha sido puesta en duda. A nivel metodológico, ha sido remarcado que las preguntas internas utilizadas por los investigadores sobre la norma de internalidad no contienen proposiciones fundadas en explicaciones estrictamente "autocentradas" (por ejemplo, "Si mi patrón, me paga un buen salario, es porque yo trabajo mucho"; "Si no obtengo la promoción, es porque no soy lo suficientemente competente"). Constamos que los individuos (ya sea porque trabajan o no lo hacen, porque tienen la competencia o no la tienen) asignan respuestas internas más que externas.

Además, se ha encontrado que respecto de aquellos ítems, que describen al actor como libre, dueño de asumir voluntariamente distintos comportamientos, se asumen respuestas externas socialmente aceptadas (Gangloff 1997a, 1997b, 1998, 1999). Es decir que, si efectivamente, se valorizan ciertas explicaciones, esa valorización influye tanto sobre las explicaciones internas como sobre las externas; esto significa que la internalidad no es el criterio diferenciador. En tal caso, la norma valorizada no sería la internalidad, sino otra cuestión. En este sentido, bien podría ser que esta valorización se moviera más en el plano de la obediencia versus la rebeldía del actor. Valorizamos a los individuos obedientes, es decir, aquellos que operan de manera interna, pero interna auto-centrada, y desvalorizamos aquellos que tanto de manera interna como evocando al ambiente social, pretenden cuestionar y transformar el orden establecido, pudiendo ser así una fuente de rebelión. Estos

\footnotetext{
6 Desde nuestro punto de vista, hablar de normalización social no excluye la posibilidad de hablar igualmente de sesgo. En este sentido, el sesgo sigue presente pero será el fruto no de cuestiones de personalidad, sino de una normalización social. Serían elementos no gratuitos (como los sesgos clásicos) pero con una función social (lo que ha conducido a hablar de "sesgos funcionales": Gangloff, 2005).

Volumen 9, Número 2, Año 2009, ISSN 1409-4703
} 
últimos se arrogarían así, prerrogativas que se reservan habitualmente a los individuos de jerarquía superior, que se atribuyen ese tipo de derechos, dejando su lugar de simples ejecutantes en este mismo esquema para pasar a ser los transformadores de la estructura de poder preexistente. En consecuencia, bien podría ser que sea no la norma de internalidad, sino la norma de obediencia la que deberíamos explorar (cf., para una revisión, Gangloff, 2000, pp. 129-180). Sin embargo, los únicos estudios relacionados con la norma de obediencia refieren al LOC. Nuestra pretensión es, entonces, realizar un estudio de la obediencia asociada al LOC y al LOD y su atribución.

Nuestra hipótesis principal es entonces que los agentes asignadores de sanciones serían más valorizados cuando ellos se declaran irresponsables de aquellas sanciones que distribuyen, con respecto a aquellos que se atribuyen la responsabilidad por tal distribución (rechazando así esa responsabilidad hacia los receptores de esas sanciones y protegiéndose de esta manera, contra eventuales planteos).

Para demostrarlo, nos situamos en el campo de los refuerzos distribuidos por los docentes a sus estudiantes. Operacionalmente hablando, estamos interesados en las explicaciones de los comportamientos distributivos de refuerzos, explicaciones que son realizadas por los docentes por un lado (LOD), y por los estudiantes receptores de esos refuerzos, por el otro (LOC).

\section{Metodología}

Este trabajo consta de dos partes, a partir de la aplicación de dos paradigmas clásicamente empleados para verificar la existencia de una norma (cf. Jellison y Green, 1981), el paradigma de la autopresentación (primer parte), y el paradigma de los juicios (segunda parte).

En la primera parte, pedimos a 90 docentes de la universidad ${ }^{7}$ que respondan a un cuestionario acerca de la atribución de sus comportamientos distributivos de recompensas y sanciones a sus estudiantes. Dichos docentes fueron seleccionados de forma aleatoria y

\footnotetext{
7 Se trata de los 90 docentes de la Licenciatura en Administración de la Facultad de Ciencias Económicas de la Universidad Nacional del Centro de la Provincia de Buenos Aires, $50 \%$ de género femenino. Volumen 9, Número femenino.
Voño 2009, ISSN 1409-4703
} 
divididos en tres grupos de 30 docentes cada uno; así, 1/3 de los docentes respondieron de la manera más honesta posible (consigna neutra), 1/3 tratando de caer bien a los estudiantes (consigna sobrenormativa) y $1 / 3$ tratando de verse mal (consigna contranormativa).

El cuestionario (cf. anexo) está constituido por 16 ítems, 8 hacen referencia a recompensas -son positivas- y 8 hacen referencia a castigos -son negativas-. Cada una de las preguntas tiene tres posibilidades de respuesta no exclusiva entre ellas: una atribuye la responsabilidad de la distribución de la sanción a los estudiantes (por sus conductas o sus características de personalidad), la segunda apunta a la personalidad o el humor actual del docente $^{8}$, y la tercera, a causas externas tanto a los estudiantes como a los docentes (reglas administrativas o contexto coyuntural). Los docentes deben expresar su grado de acuerdo/desacuerdo en la atribución de un valor que oscila entre 0 (desacuerdo total) a 10 (acuerdo total). Para cada pregunta, el máximo de puntos es de 30 , mientras que para el total del cuestionario es de 480.

Los análisis estadísticos (por t de Student) se realizan globalmente por una parte, y dicotomizando el cuestionario en dos, en función de la valencia de los ítems presentados (recompensas vs. castigos).

Para la segunda parte del estudio, reutilizamos el cuestionario precedente, pero con dos particularidades: por una parte, escindimos el cuestionario en dos según la valencia de los ítems (uno con recompensas y el otro con castigos). Por otra parte, el cuestionario ya está completo con modalidad discreta, de acuerdo a una sola de las 3 propuestas. Más precisamente, pretendemos que los docentes ya habian respondido al cuestionario, y pedimos a los 60 estudiantes $^{9}$ que ordenaran estas respuestas de los profesores según sus preferencias. Así, cada estudiante es confrontado con dos series de tres sub-cuestionarios. Uno ha sido respondido en forma auto-atribuida, otro con conductas que apuntan a los estudiantes, y el tercero, a causas externas. Para controlar un eventual efecto de orden, 30 alumnos han respondido primero los 3 sub-cuestionarios de ítems positivos y luego los 3 sub-cuestionarios de ítems negativos, mientras que la otra mitad, lo ha hecho en el orden inverso.

\footnotetext{
8 Utilizamos aquí unos de los ítems explicativos de Beauvois y Le Poultier (1966) en sus cuestionarios de atribución.

9 Se trata en su totalidad, de alumnos de tercer año de la Licenciatura en Administración de la Facultad de Ciencias Económicas de la Universidad Nacional del Centro de la Provincia de Buenos Aires, 50\% de género femenino. Volumen 9, Número 2, Año 2009, ISSN 1409-4703
} 
Los análisis estadísticos (t de Student) son realizados por un lado, globalmente y, por la otra, en forma específica: según las preferencias de los estudiantes en relación con la forma en que los docentes atribuyen sus recompensas, por un parte, y castigos, por el otro.

\section{Resultados}

\subsection{Las atribuciones realizadas por los docentes}

Globalmente, es decir, independientemente de la valencia de las sanciones, se observa que los docentes (tabla 1), tanto en consigna sobrenormativa como en consigna neutra (es decir, espontáneamente), atribuyen prioritariamente los refuerzos que ellos distribuyen, a los propios estudiantes; luego (de manera igualitaria) al contexto legal y a sí mismos (las diferencias entre la atribución a los estudiantes y la atribución a los dos siguientes factores es significativa, con un $p<0.0001$ ). Por el contrario, en consigna contranormativa, es decir, tratando de dar una mala imagen, los docentes atribuyen la causa de las sanciones primero a los estudiantes o a ellos mismos, y por último, al contexto (con una diferencia significativa, respecto de la atribución a los estudiantes o a ellos mismos con un $p=.0003)$.

\begin{tabular}{|l|c|c|c|}
\hline & Sí mismo & Estudiantes & Contexto \\
\hline Consigna sobrenormativa & 59,5 & 94,67 & 63,87 \\
\hline Consigna neutra & 45,3 & 92,43 & 46,27 \\
\hline Consigna contranormativa & 82,53 & 90,97 & 68,17 \\
\hline
\end{tabular}

Tabla 1: Promedios de atribuciones de docentes para los refuerzos positivos y negativos (correspondientes a 16 items) en función de la consigna (consigna sobrenormativa = para dar una buena imagen; consigna neutra= responder honestamente; consigna contanormativa $=$ para dar una mala imagen). Máximo para la atribución=160.

Es importante recalcar que la valencia del refuerzo no modifica en forma fundamental, la jerarquía de atribuciones obtenidas. Si se tienen en cuenta sólo las recompensas (tabla 2), se observa que los docentes, tanto en forma espontánea (consigna neutra) como para dar una buena imagen (consigna sobrenormativa) atribuyen prioritariamente los refuerzos que ellos distribuyen primero, a los estudiantes, y luego (de manera igualitaria) al contexto y a sí mismos. Las diferencias entre la atribución a los estudiantes y a las dos siguientes, son todas significativas con un $p<0.0001$. Por el contrario, en el caso de dar una mala imagen (consigna contranormativa), no se observan diferencias significativas. 


\begin{tabular}{|l|c|c|c|}
\hline & Sí mismo & Estudiantes & Contexto \\
\hline Consigna sobrenormativa & 38,23 & 55,43 & 38,97 \\
\hline Consigna neutra & 28,23 & 49,47 & 31,37 \\
\hline Consigna contranormativa & 36,77 & 38,53 & 31,77 \\
\hline
\end{tabular}

Tabla 2: Promedios de atribuciones de docentes para los refuerzos positivos (correspondientes a 8 items) en función de la consigna (consigna sobrenormativa = para dar una buena imagen; consigna neutra= responder honestamente; consigna contanormativa= para dar una mala imagen). Máximo para la atribución=80.

Si tomamos tan sólo las sanciones negativas (tabla 3), se constata del mismo modo, que los docentes, tanto espontáneamente (consigna neutra), como para dar una buena imagen (consigna sobrenormativa), atribuyen en prioridad los refuerzos que distribuyen, primero a los estudiantes, luego (de manera igualitaria) al contexto y a sí mismos (las diferencias entre la atribución a los estudiantes y a las dos causas siguientes son significativas en todos los casos, con un $\mathrm{p}<0.0002$ ). En caso contrario, para dar una mala imagen (consigna contranormativa), los docentes atribuyen el origen de sus sanciones primero a los estudiantes y a sí mismos, y por último, al contexto (con una diferencia significativa en relación a la atribución a los estudiantes, con un $p=.001$ ).

\begin{tabular}{|lc|c|c|}
\hline & Si mismo & Estudiantes & Contexto \\
\hline Consigna sobrenormativa & 21,27 & 39,23 & 24,90 \\
\hline Consigna neutra & 17,07 & 42,97 & 14,90 \\
\hline Consigna contranormativa & 45,77 & 52,43 & 36,40 \\
\hline
\end{tabular}

Tabla 3: Promedios de atribuciones de docentes para los refuerzos negativos (correspondientes a 8 items) en función de la consigna (consigna sobrenormativa = para dar una buena imagen; consigna neutra= responder honestamente; consigna contanormativa= para dar una mala imagen). Máximo para la atribución= 80 .

\subsection{Las preferencias de los estudiantes}

Tanto en términos globales como en términos según la valencia de las sanciones, se observa (tablas 4 y 5 ) una notoria preferencia de los estudiantes por los docentes que consideran a los estudiantes responsables de los refuerzos (la diferencia respecto de los otros dos tipos de docentes es significativa con un $p<0,01)$. Los docentes que refieren al contexto son ubicados en segunda posición, y los docentes auto-atribuidos se ubican en la 
última posición (la diferencia entre estos dos perfiles es significativa, con un $\mathrm{p}<0,01$ ). Es decir que los docentes tienen conciencia de las preferencias de sus alumnos (cf. supra).

\begin{tabular}{|l|c|c|c|}
\hline & $\begin{array}{c}\text { Docentes auto- } \\
\text { atribuidos }\end{array}$ & $\begin{array}{c}\text { Docentes que atribuyen } \\
\text { a sus estudiantes }\end{array}$ & $\begin{array}{c}\text { Docentes que } \\
\text { atribuyen al contexto }\end{array}$ \\
\hline Recompensas & 2,87 & 1,13 & 2,00 \\
\hline Sanciones & 2,68 & 1,42 & 1,90 \\
\hline Globalmente & 2,78 & 1,28 & 1,95 \\
\hline
\end{tabular}

Tabla 4: Clasificación por parte de los estudiantes de los docentes, para recompensas y sanciones. 1 = docente más apreciado; $3=$ docente menos apreciado.

\begin{tabular}{|l|l|l|l|}
\hline & \multicolumn{1}{|c|}{$\begin{array}{c}\text { Docentes que } \\
\text { atribuyen a sus } \\
\text { estudiantes }\end{array}$} & $\begin{array}{c}\text { Docentes que } \\
\text { atribuyen al } \\
\text { contexto }\end{array}$ \\
\hline Recompensas & Docentes auto-atribuidos & $\mathrm{t}=24,49(\mathrm{p}<0,01)$ & $\mathrm{t}=8,99(\mathrm{p}<0,01)$ \\
\cline { 2 - 4 } & $\begin{array}{l}\text { Docentes que atribuyen } \mathrm{a} \\
\text { sus estudiantes }\end{array}$ & & $\mathrm{t}=8,26(\mathrm{p}<0,01)$ \\
\hline Sanciones & Docentes auto-atribuidos & $\mathrm{t}=10,28(\mathrm{p}<0,01)$ & $\mathrm{t}=5,41(\mathrm{p}<0,01)$ \\
\cline { 2 - 4 } & $\begin{array}{l}\text { Docentes que atribuyen } \mathrm{a} \\
\text { sus estudiantes }\end{array}$ & & $\mathrm{t}=3,12(\mathrm{p}<0,01)$ \\
\hline Globalmente & $\begin{array}{l}\text { Docentes auto-atribuidos } \\
\text { Docentes que atribuyen } \mathrm{a}\end{array}$ & $\mathrm{t}=20,30(\mathrm{p}<0,01)$ & $\mathrm{t}=7,12(\mathrm{p}<0,01)$ \\
& $\begin{array}{l}\mathrm{t} \\
\text { sus estudiantes }\end{array}$ & & \\
\hline
\end{tabular}

Tabla 5: t y p obtenidos.

\section{Conclusión}

Cuando se trata de explicar de forma espontánea, es decir, bajo consigna neutra, un comportamiento (de nosotros o de otros en relación con nosotros), existe consenso en la literatura en señalar que nuestras atribuciones son sistemáticamente internas. En nuestro primer estudio, hemos observado, sin embargo, resultados inversos: bajo consigna neutra y cualquiera sea la valencia del refuerzo, los docentes atribuyen sus comportamientos distributivos de refuerzos a causas externas (en este caso, sus estudiantes) y dejan 
relegados los factores internos a la última posición (al igual que hacen con los factores resultado del contexto).

He aquí una contradicción que ilustra el reduccionismo de las investigaciones habitualmente realizadas en el dominio de la atribución: los investigadores han dejado de lado, en efecto, el examen de los comportamientos distributivos de sanciones. En consecuencia, no estudian más que un conjunto restringido de comportamientos, aunque tienden a considerar los resultados que obtienen como aplicables a la totalidad de los comportamientos. Nuestros resultados subrayan el carácter abusivo de una generalización de este tipo. En efecto, considerar al destinatario de un refuerzo como fuente de ese refuerzo (resultado habitual obtenido desde el punto de la vista de la norma de internalidad), entonces, y como corolario, esto no puede más que conducir a que quien distribuya esos refuerzos no se auto-atribuya su comportamiento de distribución de los mismos.

Desde un punto de vista normativo, los resultados tanto del segundo como del primer estudio, comparando los resultados obtenidos bajo consignas sobrenormativas en relación a las consignas contranormativas, ponen en evidencia una valorización de los docentes que consideran a los estudiantes responsables de sus éxitos y sus fracasos, y como corolario, una valorización de los docentes que se declaran irresponsables de los refuerzos que distribuyen. Estos hallazgos deberían ser analizados en conjunto con los numerosos estudios en los que se ha encontrado una valorización de las personas que se atribuyen de manera auto-centrada la causa de los refuerzos que reciben, por ejemplo, las personas que atribuyen sus éxitos a su trabajo o a sus capacidades, y que atribuyen sus fracasos a la falta de esfuerzo o ausencia de capacidades. En otros términos, la desvalorización del docente que se auto-atribuye los refuerzos que distribuyen, en concordancia con la valorización (descripta por la literatura sobre la norma de internalidad) de las personas auto-atributivas de los refuerzos que reciben, conduce a pensar que esas personas estrictamente autocentradas, excluyen toda responsabilidad al ambiente social al que llegan; en otros términos, manifiestan conductas de total obediencia al sistema social, permitiendo así la perpetuación del statu quo.

Señalamos, para terminar, que la presente investigación no es más que el inicio de una serie de trabajos similares. En estos momentos estamos revisando los resultados de otros estudios sobre atribución, obtenidos en situación de competencia entre individuos y entre grupos, en donde los sujetos deben señalar las causas de sus éxitos y fracasos, tanto como las causas de los éxitos y fracasos de sus competidores. En este sentido, nos parece Volumen 9, Número 2, Año 2009, ISSN 1409-4703 
pertinente estudiar posteriormente con precisión, las atribuciones realizadas en el ámbito de la política. Como hemos señalado más arriba, pareciera que los hombres políticos, cuando están en el poder y anuncian nuevas medidas para sus administrados (medidas a menudo, dolorosas) evitan atribuirse la responsabilidad y se refugian en causas externas (como la competencia internacional, la globalización, las reglas jurídicas supra-nacionales, etc.). Esto recuerda la "estrategia del lavabo", el "yo me lavo las manos" iniciado hace ya veinte siglos atrás por Poncio Pilatos. Creemos necesarios estudios experimentales en este dominio.

\section{Referencias}

Beauvois, Jean-Léon y Le Poultier, François. (1986). Norme d'internalité et pouvoir social en psychologie quotidienne. Psychologie Française, 31 (2), 100-108.

Dubois, Nicole. (1994). La norme d'internalité et le libéralisme. Grenoble: PUG.

Gangloff, Bernard. (1997a). Les implications théoriques d'un choix d'items: de la norme d'internalité à la norme d'allégeance. Pratiques Psychologiques, 2, 99-106.

Gangloff, Bernard. (1997b). La norme d'internalité: les tribulations d'une notion dans l'univers de l'évaluation professionnelle. Psychologie du Travail et des Organisations, 3 (1-2), 61-75.

Gangloff, Bernard. (1998). Niveau hiérarchique, style de management et infortunes de la norme d'internalité. Revue Québécoise de Psychologie, 19 (2), 29-45.

Gangloff, Bernard. (1999). Compléments à la norme d'allégeance : les bons et les mauvais externes. Communication au $4^{\text {me }}$ Colloque International de Psychologie Sociale Appliquée. Rennes (France).

Gangloff, Bernard. (2000). Profession recruteur, profession imposteur. Paris: L'Harmattan.

Gangloff, Bernard. (2004). Le parapluie de Ponce Pilate, ou la valorisation de l'externalité en matière d'explication des comportements distributifs de sanctions (Locus of Distribution). Psychologie du Travail et des Organisations, 10 (4), 313-326.

Gangloff, Bernard. (2005). Vers une théorie fonctionnaliste des biais épistémologiques : application aux biais du Big Five. In: G. Pithon y B. Gangloff (Eds.). Evaluer pour former, orienter et apprécier le personnel. Paris: L'Harmattan, 249-290.

Heider, Fritz. (1944). Social perception and social causality. Psychological Review, 51, 358374. 
Jellison, Jerald y Green, Jane. (1981). A self-presentation approach to the fundamental attribution error: the norm of internality. Journal of Personality and Social Psychology, 40 (4), 643-649.

Jones, Edouard. (1979). The rocky road from acts to dispositions. American Psychologist, $34(2), 107-117$.

Langer, Ellen. (1975). The illusion of control. Journal of Personality and Social Psychology, 32 (2), 311-328.

Lefcourt, Herbert. (1966). Internal versus external control of reinforcement : a review. Psychological Bulletin, 65, 206-220.

Lerner, Melvin. (1965). Evaluation of performance as a function of performer's reward and attractiveness. Journal of Personality and Social Psychology, 1, 355-360.

Lerner, Melvin y Simmons, Carolyn. (1966). Observer's reaction to the "innocent victim": compassion or rejection? Journal of Personality and Social psychology, 4 (2), 203220.

Nietzsche, Friedrich (éd. française 1968). Humain trop humain. Paris: Gallimard, vol.1.

Ross, Michael. (1977). The intuitive psychologist and his shortcomings: distortions in the attribution process. In L. Berkowitz (Ed.) Advances in experimental social psychology (pp. 173-220, v. 10). New-York: Academic Press.

Rotter, Julian. (1966). Generalized expectancies for internal versus external control of reinforcement. Psychological Monograph, 80 (609), 1-28.

Zuckerman, Marvin. (1979). Attribution of success and failure revised, or: the motivational bias is alive and well in attribution theory. Journal of Personality, 47, 245-287. 


\section{Anexo: cuestionario}

1. Cuando a veces felicito, es porque:

- estoy de buen humor

- los estudiantes se muestran perseverantes

- es una técnica de motivación

2. Cuando a veces sanciono muy negativamente las faltas, es porque:

- los estudiantes no son rigurosos

- necesito sentar mi autoridad

- me han pedido que sea más severo con los estudiantes

3. Cuando a veces recalco las respuestas pertinentes o correctas, es porque:

- me han pedido que motive al grupo

- estoy de buen humor

- los estudiantes se muestran capaces de realizar esfuerzos reales, efectivos

4. Cuando a veces hago observaciones desagradables, es porque:

- estoy de mal humor

- me han pedido que prepare a los estudiantes a las condiciones difíciles que van a enfrentar

- los estudiantes manifiestan comportamientos inaceptables

5. Cuando a veces califico con notas bajas es porque:

- los estudiantes han obtenido malos resultados

- las condiciones de aprobación fueron esta vez, demasiado fáciles

- he decidido ser más severo

6. Cuando a veces doy un feedback o retroalimentación unicamente positivos, es porque;

- respondo a objetivos oficiales de establecer y mantener la confianza en sí mismos de los estudiantes

- los estudiantes se lo merecen

- pienso que eso me ayuda 
7. Cuando a veces sanciono un retardo o atraso es porque:

- soy una persona de principios

- los estudiantes son por naturaleza demasiado negligentes

- por presiones u obligaciones severas que nos son impuestas

8. Cuando a veces autorizo pausas más largas, es porque:

- los estudiantes son lentos, pesados

- deseo que los estudiantes me estimen

- excepcionalmente, un colega me ha pedido y demorado durante la pausa

9. Cuando a veces destaco los buenos ejemplos del trabajo hecho, es porque:

- se ha decidido que apliquemos una pedagogía compartida, común

- me gusta motivar

- los estudiantes son trabajadores

10. Cuando a veces doy como trabajo ejercicios más difíciles, es porque:

- estoy irritado porque no logro lo que quiero

- se exige más desde el programa pedagógico del curso

- algunos estudiantes no se esfuerzan

11. Cuando a veces destaco los nombres de aquellos con inquietudes de mayor interés es porque:

- los estudiantes persiguen un reconocimiento

- la evaluación necesita incluir elementos subjetivos como el interés

- me gustan las preguntas o inquietudes que me estimulan

12. Cuando a veces llamo la atención en voz alta por ciertas ausencias es porque:

- es una regla administrativa

- ciertos estudiantes tienen muchas ausencias

- yo le doy importancia a la asistencia en mis cursos. 
13. Cuando a veces decido no dar por aprobado el curso es porque:

- pienso que los criterios son demasiado flexibles

- ciertos estudiantes son lentos para asimilar

- la consigna es no regalar el curso

14. Cuando a veces exalto los buenos elementos o fortalezas del grupo, es porque:

- los estudiantes disfrutan de que los distinga como que son de los mejores

- pienso que la pedagogía del ejemplo, funciona

- el objetivo principal del curso es llevar a cada uno al máximo de sus potencialidades

15. Cuando a veces pido a un estudiante que cambie de lugar es porque:

- me han dado una sala que da directamente a una calle ruidosa

- no me puedo concentrar

- ciertos estudiantes tienen tendencia a distraerse

16. Cuando a veces autorizo el paso a un nivel superior es porque:

- el estudiante muestra que es capaz

- en nuestros cursos, se necesita una tasa mínima de aprobación

- no quiero tener recursantes en mi curso el año que viene. 